\title{
Pengelolaan Laboratorium Kimia Kimia Di SMAN 1 Kupang Nusa Tenggara Timur (NTT)
}

\author{
Yanti Rosinda Tinenti", Hironimus Tangi, Yustina D. S. Lawung \\ Fakultas Keguruan dan Ilmu Pendidikan \\ Universitas Katolik Widya Mandira (Unwira) \\ Email: yantitinenti@gmail.com
}

\begin{abstract}
This PKM is conducted at SMA Negeri I Kupang, which is located at JLN. Cak Doko, No. 59, Oetete Village, Oebobo District, Kupang City, NTT Province.

The problem experienced is that the existing chemical laboratory is not well organized. Most of the tools and materials are still in the package and have not been properly arranged, making it difficult for the teacher to prepare the tools and materials when doing practicum in the laboratory or in the classroom during the learning process. The absence of laboratory assistants means that the types of administration that should be owned by a laboratory are completely unavailable. The solution is to organize the laboratory in accordance with the rules for arranging tools and materials. Use shelves and cabinets to store tools and materials that are still in the package. Together with the teacher, arrange and procure the types of administration that a laboratory must have.

The output in this PKM is a well-organized chemical laboratory, producing types of laboratory administration, analyzing the increase in teacher knowledge and skills regarding laboratory administration and governance.

The result of this PKM activity was an increase in the value of the ability of teachers in laboratory management and administration which had an impact on the conditions of the chemistry laboratory at SMAN 1 Kupang on 5 governance indicators indicated by $N$-Gain values and criteria consecutively as follows, planning indicator 0, 62 (moderate), organizing indicator 0.33 (moderate), administration indicator 0.78 (high), laboratory instrument arrangement indicator 1 (high), laboratory material structuring indicator 0.93 (high), and safety indicator 0.67 ( moderate). Thus it can be concluded that this PKM activity can improve teachers' knowledge and skills regarding laboratory governance.
\end{abstract}

Keywords: Laboratory management

\begin{abstract}
Abstrak
PKM ini dilakukan di SMA Negeri I Kupang yang beralamat JLN. Cak Doko, No. 59, Kelurahan Oetete, Kecamatan Oebobo, Kota Kupang, Provinsi NTT. Permasalahan yang dialami yakni laboratorium kimia yang ada belum tertata dengan baik. Sebagian besar alat dan bahan masih terdapat dalam kemasan dan belum di tata dengan baik sehingga menyulitkan guru dalam mempersiapkan alat dan bahan ketika akan melakukan praktikum di laboratorium maupun di kelas saat proses pembelajaran. Tidak terdapatnya tenaga laboran mengakibatkan jenis-jenis administrasi yang harusnya dimiliki oleh suatu laboratorium sama sekali belum tersedia. Solusinya yakni melakukan penataan laboratorium sesuai dengan aturan penataan alat dan bahan. Menggunakan rak dan lemari untuk menyimpan alat dan bahan yang masih terdapat dalam kemasan. Bersama guru menyusun dan membuat pengadaan jenis-jeins administrasi yang harus dimiliki oleh suatu laboratorium.

Adapun luaran dalam PKM ini yakni laboratorium kimia tertata dengan baik, menghasilkan jenisjeins administrasi suatu laboratorium, menganalisis peningkatan pengetahuan dan keterampilan guru mengenai administrasi dan tata kelola laboratorium.
\end{abstract}


Hasil dari kegiatan PKM ini adalah terjadi peningkatan nilai kemampuan guru dalam tata kelola dan administrasi laboratorium yang berdampak pada kondisi laboratorium kimia di SMAN 1 Kupang pada 5 indikator tata kelola ditunjukkan dengan nilai dan kriteria $\mathrm{N}$-Gain berturut-turut sebagai berikut, indikator perencanaan 0,62 (sedang), indikator pengorganisasian 0,33 (sedang), indikator pengadministrasian 0,78 (tinggi), indikator penataan alat laboratorium 1 (tinggi), indikator penataan bahan laboratorium 0,93 (tinggi), dan indikator pengamanan 0,67 (sedang). Dengan demikian dapat disimpulkan bahwa kegiatan PKM ini dapat meningkatkan pengetahuan dan keterampilan guru mengenai tata kelola laboratorium

Kata Kunci: Pengelolaan laboratorium

\section{PENDAHULUAN}

Menurut Peraturan Pemerintah (PP) Nomor 19 Tahun 2005 tentang Standar Nasional Pendidikan Laboratorium serta jenis perlatan dan bahan yang terdapat didalamnya merupakan sarana dan prasarana yang penting untuk menunjang proses pembelajaran di sekolah. Laboratorium pula merupakan salah satu sarana pendidikan yang dapat digunakan sebagai tempat bagi peserta didik untuk mengadakan kontak langsung dengan objek yang dipelajari secara langsung baik melalui proses pengamatan, maupun secara langsung melakukan percobaan.

Proses pembelajaran kimia di sekolah dapat terlaksana dengan baik dan dapat mengintegrasikan dengan baik proses eksperimen dan pekerjaan laboratorium apabila laboratorium yang terdapat di suatu satuan pendidikan dapat di kelola dan di manfaatkan dengan baik.

SMA Negeri I Kupang yang beralamat di JLN. Cak Doko, No. 59, Kelurahan Oetete, Kecamatan Oebobo, Kota Kupang, Provinsi NTT merupakan salah satu Sekolah Menengah Atas yang terdapat di Kota Kupang. Sekolah ini yang dijadikan mitra pada program Pengabdian Kepada Masyarakat (PKM) ini.

Berdasarkan hasil observasi yang dillakukan maka dapat diungkapkan beberapa masalah pokok yang dapat di selesaikan dalam PKM ini. Masalah tersebut antara lain laboratorium kimia yang ada belum tertata dengan baik. Sebagian besar alat dan bahan masih terdapat dalam kemasan dan belum di tata dengan baik sehingga menyulitkan guru dalam mempersiapkan alat dan bahan ketika akan melakukan praktikum di laboratorium maupun di kelas saat proses pembelajaran. Untuk itu perlu dilakukan penataan alat dan bahan di laboratorium dengan tujuan untuk memudahkan dalam proses pemeliharaan, memudahkan pengambilan alat dan bahan untuk keperluan kerja lab, memudahkan pengontrolan kuantitas maupun kualitas alat dan bahan, identitas alat dan bahan, serta presisi alat dapat terpelihara dengan baik, meminimalisir bahaya dan resiko tinggi yang dapat disebabkan oleh sifat dari bahan kimia di laboratorium.

Adapun Adminstrasi laboratorium hanya terdiri dari buku inventarisir alat dan bahan. Minimnya pengadminstrasian ini mengakibatkan pengunaan dan pengadaan alat dan bahan tidak terkontrol dengan baik. Hal yang penting yang harus dimiliki oleh suatu laboratorium kimia berkaitan dengan administrasi adalah tersedianya kartu alat dan bahan. Kartu alat dan bahan kimia memuat tentang identitas bahan kimia atau alat, serta riwayat pemakaian untuk bahan kimia dan riwayat kerusakan/perbaikan untuk alat. Data yang digunakan dalam kartu alat dan bahan kimia ini, dibuat dengan data sebenarnya untuk diketahui oleh pihak yang memerlukannya. Dengan kartu alat dan bahan kimia ini akan lebih praktis dan sistematis ketika akan mengakses riwayat kerusakan /pemeliharaan alat dan penggunaan bahan kimia karena telah tersedia di dekat alat atau bahan kimianya. Selain itu dapat dijadikan sebagai bahan acuan untuk pengadaan alat/bahan kimia jika sudah rusak atau habis. 
Selain kartu alat dan bahan jenisjenis administrasi lain yang perlu diadakan dalam suatu laboratorium adalah formulir permintaan alat dan bahan, buku harian laboratorium, kartu reparasi alat, daftar inventaris alat dan bahan sesuai dengan LKPD, program kegiatan laboratorium, jadwal kegiatan, daftar alat dan bahan yang rusak, daftar pesanan, formulir peminjaman alat dan bahan. Semua jenis administrasi ini akan mempermudah pengelola laboratorium dalam menjalankan laboratorium tersebut sesuai dengan fungsinya, serta penggunaan alat dan bahan dapat terkontrol dengan baik.

Hasil observasi lainnya adalah sudah terdapat tata tertib laboratorium namun hal-hal yang berkaitan dengan keamanan kerja saat melakukan praktikum seperti perlindungan diri (personal protection), penanganan darurat (emergensi respons), penanganan limbah kimia (chemical waste disposal), kemanan kerja (work safety), teknik penggunaan peralatan dasar belum terintegrasi dengan baik dalam tata tertib tersebut. Selain itu Belum ada sosialsisasi secara mendalam kepada peserta didik tentang tata tertib laboratorium.

Berdasarkan permasalahan yang telah di uraikan pada bagian pendahuluan maka berikut akan diuraikan solusi yang dapat mengatasi masalah-masalah mitra tersebut yang merupakan tujuan yang telah dilakukan dalam PKM ini.

\section{Melakukan workshop untuk menyusun tata tertib laboratorium.}

Pada kegiatan ini guru kimia di himpun untuk menyusun tata tertib labotratorium yang mengintegrasikan empat aspek penting yakni perlindungan diri (personal protection), penanganan darurat (emergensi respons), penanganan limbah kimia (chemical waste disposal), kemanan kerja (work safety), teknik penggunaan peralatan dasar. Tata tertib tersebut kemudian perlu disosialisasikan kepada pengguna laboratorium dalam hal ini peseta didik. Sosialisasi dapat dilakukan dengan cara tata tertib di cetak dalam bentuk poster dan di tempelkan pada beberapa bagian dari laboratorium, maupun diinitegrasikan dalam setiap Lemari Kegiatan Peserta Didik (LKPD) yang di kembangkan oleh guru, sebagai pedoman dalam melakukan eksperimen atau praktikum di laboratorium.

2. Melakukan workshop untuk menyusun jenis-jenis administrasi yang harus dimiliki oleh laboratorium kimia,

Pada kegiatan ini hal yang harus dilakukan adalah guru yang berperan sebagai pengelola laboratorium bersama-sama dengan pelaksana kegiatan PKM menyusun kartu alat, kartu bahan, daftar inventarisir alat dan bahan, formulir penggunaan alat-dan bahan sesuai dengan jenis eksperimen, kartu reparasi alat, jadwal penggunaan laboratorium, program kerja laboratorium dan standar operasioanal penggunaan laboratorium. Hal ini di dahuli dengan menginventarisir semua jenis alat dan bahan yang tedapat dilaboratorium. Agar meringankan dalam pelaksanaan kegiatan ini, pelaksana PKM akan melibatkan 10 orang mahasiswa yang memprogramkan mata kuliah pengelolaan laboratorium.

3. Bersama guru dan mahasiswa melakukan penataan alat dan bahan yang terdapat dalam laboratorium kimia,

Pada kegiatan ini guru pengelola laboratorium bersama pelaksana PKM dan mahasiswa melakukan penataan alat dan bahan di laboratorium berdasarkan standar penataan alat dan bahan. Dalam menata alat dan bahan tersebut, jenis administrasi yang perlu di lengkapi seperti kartu alat dan bahan di letakkan pada masing-masing jenis alat dan bahan.

\section{METODE PENGABDIAN}

Tahap-tahap kegiatan PKM terdiri dari:

\section{Tahap Persiapan}

Adapun hal-hal yang dilakukan oleh pelaksana PKM pada tahap ini antara lain 
a. Melakukan komunikasi dengan guruguru kimia dan pengelola laboratorium di sekolah untuk menentukan waktu pelaksanaan PKM,

b. Mempersiapkan materi tentang aspekaspek tata tertib laboratorium, jenisjenis administrasi dan tata kelola laboratorium,

c. Mempersiapkan mahasiswa yang akan dilibatkan dalam kegiatan PKM ini,

d. Mengembangkan instrumen untuk menghimpun data tentang kemampuan guru dalam mengelola laboratorium (tata kelola dan administrasi laboratorium.

\section{Tahap Pelaksanaan}

Adapun hal-hal yang dilakukan oleh pelaksana PKM pada tahap ini antara lain

a. Menyebarkan instrumen untuk menghimpun data tentang kemampuan awal guru dalam mengelola laboratorium (tata kelola dan administrasi laboratorium,

b. Melakukan workshop untuk menyusun tata tertib laboratorium yang meliputi aspek perlindungan diri (personal protection), penanganan darurat (emergensi respons), penanganan limbah kimia (chemical waste disposal), kemanan kerja (work safety), teknik penggunaan peralatan dasar,

c. Melakukan workshop untuk menyusun jenis-jenis administrasi yang harus dimiliki oleh laboratorium kimia,

d. Bersama guru dan mahasiswa melakukan penataan alat dan bahan yang terdapat dalam laboratorium kimia,

\section{Tahap Evaluasi}

Adapun hal-hal yang dilakukan oleh pelaksana PKM pada tahap ini antara lain

a Memberikan kuisioner untuk mengetahui kemampuan akhir guru dalam mengelola laboratorium (tata kelola dan administrasi laboratorium)

b. Penyusunan laporan akhir.

Teknik dan Instrumen Pengumpulan Data
Teknik pengumpulan data dalam PKM ini adalah triangulasi teknik, dimana menggunakan lebih dari satu teknik yang berbeda untuk mengumpulkan data dari sumber yang sama (sugiono 2014:330). Teknik pengumpulan data yang digunakan yaitu observasi, dan wawancara.

Selanjutnya instrumen yang digunakan untuk mengumpulkan data dalam PKM ini adalah lembar obsevasi dan panduan wawancara tentang tata kelola dan administrasi laboratorium kimia SMA.

Instrumen pengumpulan data ini dikembangkan berdasarkan aspek pengelolaan laboratorium yang disyaratkan dalam Permendiknas No.24 Tahun 2007 dalam Mariza,dkk (2017). Terdapat lima aspek pengelolaan laboratorium yakni: perencanaan, pengorganiisasian, pengadministrasian, penataan, dan keamanan. Aspek-aspek ini kemudian dijadikan sebagai indikator untuk mengembangkan pertanyaanpertanyaan wawancara, dan panduan observasi untuk mendapatkan data kuantitatif tentang tata kelola dan pengadministrasian laboratorium.

\section{Teknik Analisis Data}

Adapun teknik analisis data dalam PKM ini adalah deskriptif kuantitatif. Data kuantitatif diperoleh melalui hasil observasi yang berkaitan dengan ketersediaan setiap aspek dalam lima indikator tata kelola dan administrasi laboratorium. Adapun skor yang diperoleh didasarkan pada:

Skor 1 apabila aspek yang diobservasi tersedia

Skor 0 apabila aspek yang diobservasi tidak tersedia

Data kuantitatif hasil wawancara dan observasi kemudian dianalisis dengan menggunakan persamaan:

Nilai $=\frac{\text { Skorhasilwawancaradanobservasi }}{\text { Skormaksimum }} \times 100$

Adapun wawancara dan observasi ini dilakukan sebelum dan sesudah kegiatan 
PKM . dengan demikian akan dianalisis peningkatan nilai tata kelola dan administrasi laboratorium dengan menggunakan persamaan N-Gain. Persamaan tersebut dapat dinyatakan sebagai berikut:

$N-$ gain $=\frac{\text { Nilai awal }- \text { Nilai akhir }}{\text { Nilaimaksimum/ ideal }- \text { Nilai akhir }}$

Setelah diperoleh nilai $\mathrm{N}$-gain, nilai tersebut kemudian dapat dideskripsikan berdasarkan kriteria yang terdapat pada tabel 2 .

Tabel 2. Kriteria Nilai N-gain

\begin{tabular}{|l|l|}
\hline Nilai N-gain & Kriteria \\
\hline N-Gain $\geq 0.70$ & Tinggi \\
\hline $0.30<$ N-Gain $<0.70$ & Sedang \\
\hline N-Gain $\leq 0.30 \quad$ Rendah \\
\hline \multicolumn{2}{|c|}{ (Diadaptasi dari Lestari dan }
\end{tabular}

Yudhanegara, 2015)

\section{HASIL DAN PEMBAHASAN}

Peningkatan Pengetahuan dan Keterampilan Guru Dalam Tata Kelola dan Adminstrasi Serta Kondisi Laboratorium Kimia SMAN 1 Kupang Dalam melihat peningkatan pengetahuan dan keterampilan guru dalam tata kelola dan adminstrasi serta kondisi laboratorium kimia SMAN 1 Kupang, maka pembahasan akan didasarkan pada hasil analisis data peningkatan berdasarkan nilai $\mathrm{N}-$ Gain pada tabel 1.

Tabel 1.

Hasil analisis data N-Gain Peningkatan Pengetahuan dan Keterampilan Guru Dalam Tata Kelola dan Adminstrasi Serta Kondisi Laboratorium Kimia SMAN 1 Kupang

\begin{tabular}{|c|c|c|c|c|c|c|c|}
\hline & $\begin{array}{l}\text { Skor } \\
\text { Maksimum } \\
\text { pada Aspek } \\
\text { Perencanaan }\end{array}$ & 8 & 8 & & & & \\
\hline \multirow{3}{*}{2} & $\begin{array}{l}\text { Nilai pada } \\
\text { Indikator } \\
\text { Pengorganisasia } \\
\mathrm{n}\end{array}$ & 25 & 50 & 25 & 75 & 0,33 & \multirow{3}{*}{ Sedang } \\
\hline & $\begin{array}{l}\text { Jumlah Skor } \\
\text { pada Indikator } \\
\text { Pengorganisasia }\end{array}$ & 1 & 2 & & & & \\
\hline & $\begin{array}{l}\text { Jumlah Skor } \\
\text { Maksimum } \\
\text { pada Indikator } \\
\text { Pengorganisasia } \\
\text { n }\end{array}$ & 4 & 4 & & & & \\
\hline \multirow{3}{*}{3} & $\begin{array}{l}\text { Nilai pada } \\
\text { Indikator } \\
\text { Pengadministras } \\
\text { ian }\end{array}$ & 18,18 & 81,82 & 63,64 & 81,82 & 0,78 & \multirow{3}{*}{ Tinggi } \\
\hline & $\begin{array}{l}\text { Jumlah Skor } \\
\text { pada Indikator } \\
\text { Pengadministras } \\
\text { ian }\end{array}$ & 2 & 9 & & & & \\
\hline & $\begin{array}{l}\text { Skor } \\
\text { Maksimum } \\
\text { pada Aspek } \\
\text { Pengadministras } \\
\text { ian }\end{array}$ & 11 & 11 & & & & \\
\hline \multirow{3}{*}{4} & $\begin{array}{l}\text { Nilai pada } \\
\text { Indikator } \\
\text { Penataan Alat } \\
\text { Laboratorium }\end{array}$ & 0 & 100 & 100 & 100 & 1 & \multirow{3}{*}{ Tinggi } \\
\hline & $\begin{array}{l}\text { Jumlah Skor } \\
\text { Pada Indikator } \\
\text { Penataan Alat } \\
\text { Laboratorium }\end{array}$ & 0 & 8 & & & & \\
\hline & $\begin{array}{l}\text { Skor } \\
\text { Maksimum } \\
\text { pada Indikator } \\
\text { Penataan Alat } \\
\text { Laboratorium }\end{array}$ & 8 & 8 & & & & \\
\hline \multirow{3}{*}{5} & $\begin{array}{l}\text { Nilai pada } \\
\text { Indikator } \\
\text { Penataan Bahan } \\
\text { Laboratorium }\end{array}$ & 17,64 & 94,11 & 76,48 & 82,36 & 0,93 & \multirow{3}{*}{ Tinggi } \\
\hline & $\begin{array}{l}\text { Jumlah Skor } \\
\text { pada Indikator } \\
\text { Penataan Bahan }\end{array}$ & 3 & 16 & & & & \\
\hline & $\begin{array}{l}\text { Skor } \\
\text { Maksimum } \\
\text { pada Penataan } \\
\text { Bahan } \\
\text { Laboratorium }\end{array}$ & 17 & 17 & & & & \\
\hline \multirow{3}{*}{6} & $\begin{array}{l}\text { Nilai pada } \\
\text { Indikator } \\
\text { Pengamanan }\end{array}$ & 57,14 & 85,71 & 28,57 & 42,86 & 0,67 & \multirow{3}{*}{ Sedang } \\
\hline & $\begin{array}{l}\text { Jumlah Skor } \\
\text { pada Indikator } \\
\text { Pengamanan }\end{array}$ & 4 & 6 & & & & \\
\hline & $\begin{array}{l}\text { Jumlah Skor } \\
\text { Maksimum } \\
\text { pada Indikator } \\
\text { Pengamanan }\end{array}$ & 7 & 7 & & & & \\
\hline
\end{tabular}

\begin{tabular}{|c|l|c|c|c|c|c|}
\hline No & $\begin{array}{c}\text { Indikator dan } \\
\text { pertanyaan }\end{array}$ & $\begin{array}{c}\text { Skor } \\
\text { awal }\end{array}$ & $\begin{array}{c}\text { Skor } \\
\text { akhir }\end{array}$ & $\begin{array}{c}\text { Nilai } \\
\text { akhir- } \\
\text { nilai } \\
\text { awal }\end{array}$ & $\begin{array}{c}\text { Nilai } \\
\text { ideal } \\
\text {-nilai } \\
\text { awal }\end{array}$ & $\begin{array}{c}\text { Nilai } \\
\text { N- } \\
\text { Gain }\end{array}$ \\
\hline \multirow{2}{*}{1} & $\begin{array}{l}\text { Nilai pada } \\
\text { indikator } \\
\text { perencanaan }\end{array}$ & 0 & 62.5 & 62.5 & 100 & 0,62 \\
\cline { 2 - 7 } & $\begin{array}{l}\text { Jumlah Skor } \\
\text { pada Indikator } \\
\text { Perencanaan }\end{array}$ & 0 & 5 & & & \\
\hline
\end{tabular}

asarkan data pada tabel 1, dapat diungkapkan bahwa peningkatan nilai kema puan guru dalam tata kelola dan admi nistrasi laboratorium yang berdampak pada kondisi laboratorium kimia diSMAN $1 \mathrm{Ku}$ pang pada 5 indikator tata kelola 
ditunjukkan dengan nilai dan kriteria NGain berturut turut sebagai berikut, indikator perencanaan 0,62 (sedang), indikator pengorganisasian 0,33 (sedang), indikator pengadministrasian 0,78 (tinggi), indikator penataan alat laboratorium 1 (tinggi), indikator penataan bahan laboratorium 0,93 (tinggi), dan indikator pengamanan 0,67 (sedang).

Berdasarkan data pada tabel 7, dapat pula dibahas beberapa hal sebagai berikut:

Pada indikator perencanaan terdapat 8 aspek yang menjadi tolak ukur dalam menentukan baik tidaknya tata kelola, administrasi dan kondisi laboratorium. Pada observasi awal, seluruh aspek tersebut belum terpenuhi dengan baik, namun pada observasi akhir setelah dilaksanakannya rangkaian kegiatan PKM, terdapat 5 aspek yang terpenuhi yakni tersedianya program kerja, tersedianya jadwal kegiatan laboratorium yang sesuai dengan program kerja yakni, tersedianya: 1) jadwal praktikum, 2) jadwal untuk menginventarisir alat dan bahan laboratorium, 3) jadwal untuk mengusulkan alat dan bahan laboratorium, 4) pembagian tugas untuk mengkoordinasikan penggunaan laboratorium. Adapun jadwal kegiatan laboratorium yang sesuai dengan program kerja yang tidak sepenuhnya terpenuhi yakni, 1) jadwal permintaan LKPD kepada guru bidang studi kimia sebagai panduan dalam melakukan praktikum, hal ini disebabkan karena waktunya belum dapat ditentukan secara pasti karena akan dilaksanakan pada semester berikutnya dan harus melibatkan guru kimia lainnya sebagai pengguna laboratorium. Meskipun demikian namun dalam kegiatan PKM telah dibuatkan format pemintaan LKPD kepada masing-masing guru kimia. Jadwal lengkapnya akan disesuaikan oleh pengelola lab. 2) Jadwal penataan laboratorium, hal ini disebabkan karena untuk melakukan penataan laboratorium, membutuhkan tenaga agar alat dan bahan dilaboratorium dapat tertata dengan baik tanpa mengabaikan syarat-syarat penting dalam penataan alat dan bahan tersebut. Kendalanya adalah pengelola laboratorium hanya terdiri dari kepala laboboratorium yang juga adalah guru kimia dengan tugas pokok melaksanakan proses pembelajaran di kelas.

Pada indikator pengorganisasian terdapat terdapat 4 aspek yang menjadi tolak ukur dalam menentukan baik tidaknya tata kelola, administrasi dan kondisi laboratorium. Pada observasi awal, terdapat 1 aspek aspek sudah terpenuhi dengan baik yakni tersdianya struktur organisasi yang jelas dalam laboratorium, dan pada observasi akhir setelah dilaksanakannya rangkaian kegiatan PKM, terdapat 1 apek lagi yang terpenuhi yakni deskripsi tugas dan tanggung jawab pengelola laboratoorium yang disahkan oleh kepala sekolah. Terdapat 2 aspek yang tidak terpenuhi yakni: 1) setiap pengelola laboratorium belum menjalankan tugas sesuai dengan tanggung jawabnya yang tertuang dalam deskripsi tugas dan tanggung jawab pengelola, 2) Proses pengorganiisasian laboratorium belum berjalan sesuai dengan struktur organisasi laboratorium, kedua hal ini baru akan diketahui keterlaksanaannya pada tahun ajaran yang baru.

Menurut Susilowati

Administrasi administrasi dalam

laboratorium merupakan suatu proses pencatatan atau inventarisasi fasilitas \& aktifitas laboratorium, supaya semua fasilitas dan aktifitas laboratorium dapat terorganisir dengan sistematis. Sejalan dengan itu diungkapkan pula oleh Verdamawan (2015:45) yang menyatakan bahwa administrasian merupakan dokumentasi seluruh sarana dan prasarana serta aktivitas laboratorium. Dalam kaitannya dengan pengadaan alat dan bahan, yang bertujuan untuk mencegah kehilangan / penyalahgunaan, memudahkan oprasional dan pemeliharaan, mencegah duplikasi / overlapping permintaan alat dan memudahkan pengecekan. Dengan 
demikian

Pada

indikator

pengadministrasian terdapat terdapat 11 aspek yang menjadi tolak ukur dalam menentukan baik tidaknya tata kelola, administrasi dan kondisi laboratorium. Pada observasi awal, terdapat 2 aspek yang terpenuhi yakni 1) tersedianya buku inventaris alat, 2) tersedianya buku inventaris bahan, namun tidak semua alat dan bahan terinventarisir dengan baik. Pada observasi akhir setelah dilaksanakannya rangkaian kegiatan PKM,seluruh alat dan bahan yang terdapat di laboratorium dapat terinventarisir dengan baik dan terdapat tambahan 7 aspek yang terpenuhi yakni: 1) tersedianya formulir permintaan alat dan bahan, 2) tersedianya kartu reparasi alat laboratorium, 3) tersedianya program kegiatan laboratorium, 4) tersedianya jadwal kegiatan laboratorium, 5) tersedianya daftar alat dan bahan laboratorium yang rusak, 6) tersedia daftar pesanan alat dan bahan laboratorium, 7) tersedianya formulir peminjaman alat dan bahan laboratorium. Terdapat 2 aspek yang tidak terpenuhi yakni: 1) tidak tersedianya buku harian laboratorium, 2) tidak tersedianya tersedia daftar inventaris alat dan bahan sesuai LKS/LKPD. Hal ini tidak tersedianya dua jenis administrasi ini disebabkan karena buku harian baru akan diisi pada tahun ajaran berikutnya dan inventarisir alat dan bahan sesuai LKS/LKPD baru akan disesuaikan dengan LKPD/LKS yang dikumpulkan dari semua guru yang mengasuh mata pelajaran kimia. Namun hasil dari kegiatan PKM ini adalah sudah tersedianya format untuk kedua jenis administrasi tersebut.

Pada indikator penataan alat

laboratorium terdapat terdapat 8 aspek yang menjadi tolak ukur dalam menentukan baik tidaknya tata kelola, administrasi dan kondisi laboratorium. Pada observasi awal, semua aspek belum terpenuhi dengan baik, sedangkan pada observasi akhir setelah dilaksanakannya rangkaian kegiatan PKM seluruh aspek dapat terpenuhi. Aspek-aspek yang terpenuhi tersebut terdiri dari: alat-alat laboratorium sudah ditata dengan baik sesuai dengan 1) fungsinya, 2) kecanggihan dan ketelitiannya, 3) keperangkatannya, 4) sifat alat termasuk kepekaan terhadap lingkungan, 5) bahan dasar penyusun alat, 6) bobot / berat alat, 7) bentuk dan ukuran alat, 8) 7 aspek sebelumnya, dan terdapat pengkombinasian aspek-aspek tersebut.

Pada indikator penataan bahan

laboratorium terdapat terdapat 17 aspek yang menjadi tolak ukur dalam menentukan baik tidaknya tata kelola, administrasi dan kondisi laboratorium. Pada observasi awal, terdapat 3 aspek yang terpenuhi yakni bahan-bahan di laboratorium sudah ditata dengan memperhatikan: 1) tingkat resiko bahaya (multiple hazards), 2) fasilitas penyimpanan (storage facilities), 3) bahan kadaluarsa (outdate chemicals) meskipun belum sepenuhnya terpenuhi karena terdapat bahan-bahan tertentu yang penataannya belum memperhatikan ketiga hal tersebut. Pada observasi akhir setelah dilaksanakannya rangkaian kegiatan PKM terdapat tambahan 13 aspek yang terpenuhi yakni bahan-bahan di laboratorium sudah ditata dengan memperhatikan 1) pemisahan (segregation), 2) pelabelan (labeling), 3) wadah sekunder (secondary containment), 4) inventarisasi (inventory), 5) informasi resiko bahaya (hazard information), 6) jumlah bahan yang disimpan, berdasarkan sifat-sifat zat seperti 7) wujud zat, 8) konsentrasi zat, 9) bahaya zat (korosif, mudah terbakar, beracun, mudah meledak, oksidator, reaktif terhadap air, reaktif terhadap asam, gas bertekanan), 10) kepekaan terhadap cahaya, 11) mudahnya zat tersebut untuk menguap, 12) mempertimbangkan aspek seberapa sering zat tersebut digunakan,13) berdasarkan pertimbangan bahwa bahan tersebut dapat diambil langsung oleh pengguna laboratorium. Sedangkan terdapat 1 aspek 
yang tidak terpenuhi setelah kegiatan PKM yakni penataan bahan berdasarkan sifat asam karena tidak tersedianya lemari asam, namun zat-zat ini ditata dengan baik di lemari biasa (lemari kayu) dan terpisah dari zat lainnya dengan memperhatikan syarat-syarat penataan yang lainnya juga. Hasil dari PKM ini sejalan dengan yang diungkapkan oleh Verdamawan (2015:44) yang menyatakan bahwa setiap bahan kimia memiliki sifat fisik dan kimia yang berbeda-beda. maka, dalam penyimpanan dan penataan bahan kimia harus diperhatikan aspek pemisahan (segregation), tingkat resiko bahaya (multiple hazards), pelabelan (labeling), fasilitas penyimpanan (storage facilities), wadah sekunder (secondary containment), bahan kadaluarsa (outdate chemicals), inventarisasi (inventory), dan informasi resiko bahaya (hazard information).

Pada indikator pengamanan terdapat terdapat 7 aspek yang menjadi tolak ukur dalam menentukan baik tidaknya tata kelola, administrasi dan kondisi laboratorium. Pada observasi awal, terdapat 4 aspek yang terpenuhi yakni 1) tersedianya tata tertib laboratorium, tata tertib dilaboratorium sudah meliputi aspek 2) perlindungan diri (personal protection), 3) penanganan darurat (emergensi respons), 4) penanganan limbah kimia (chemical waste disposal), meskipun belum lengkap dan belum terorganisir dengan baik. Pada observasi akhir setelah dilaksanakannya rangkaian kegiatan PKM, 4 aspek tersebut sudah teorganisir dengan baik dan terdapat tambahan 2 aspek yang terpenuhi yakni tata tertib dilaboratorium sudah meliputi aspek: 1) keamanan kerja (work safety), 2) administrasi (administration). Aspek yang belum terpenuhi pada observasi akhir yakni LKPD (yang dijadikan sebagai panduan praktikum) belum terdapat tata tertib laboratorium, hal ini disebabkan karena belum terdapat LKPD/LKS dari guru sebagai pengguna laboratorium. Namun hal ini telah disosialisasikan dalam kegiatan PKM bagi guru-guru agar menyertakan tata tertib lab dengan aspekaspeknya pada LKS/LKPD yang disusun nantinya.

\section{SIMPULAN}

Dalam kegiatan PKM ini dapat disimpulkan beberapa hal sebagai berikut:

1. Terjadi peningkatan nilai kemampuan guru dalam tata kelola dan administrasi laboratorium yang berdampak pada kondisi laboratorium kimia di SMAN 1 Kupang pada 5 indikator tata kelola ditunjukkan dengan nilai dan kriteria N-Gain berturut turut sebagai berikut, indikator perencanaan 0,62 (sedang), indikator pengorganisasian 0,33 (sedang), indikator pengadministrasian 0,78 (tinggi), indikator penataan alat laboratorium 1 (tinggi), indikator penataan bahan laboratorium 0,93 (tinggi), dan indikator pengamanan 0,67 (sedang)

2. Perlu dilaksanakan tata kelola laboratorium agar kondisi laboratorium dapat mendukung guru dalam meningkatkan kualitas pembelajaran kimia yang dapat mencapai aspek keterampilan maupun pengetahuan seperti yang dicanagkan dalam kurikulum 2013.

\section{UCAPAN TERIMAKASIH}

Terlaksananya program PKM ini tidak terlepas dari dukungan berbagai pihak. Oleh karena itu disampaikan terima kasih kepada:

1. LPPM Universitas Katolik Widya Mandira (UNWIRA) Kupang yang sepenuhnya membiayai kegiatan PKM ini

2. Kepala sekolah dan semua guru SMAN 1 Kupang yang telah bersedia menjadi mitra dalam kegiatan PKM ini. 


\section{DAFTAR PUSTAKA}

[1] Lestari, E,K. Yudhanegara, R, M. 2015. Penelitian Pendidikan Matematika. Bandung. PT Revika Aditama.

[2] Mariza Fiska, Afreni Hamidah, Retni S. Budiarti. 2017. Analisis Pelaksanaan Manajemen Laboratorium Pada Pembelajaran BiologiKelas XI SMA Negeri Kabupaten Muaro Jambi. Diakses tanggal 6 Februari 2021.

https://repository.unja.ac.id/2386/1/A rtikel_print.pdf

[3] Pramono Wargo. 2012. Pemahaman Guru Dalam Pengelolaanlaboratorium Fisika Di Smadan $\quad \mathrm{Ma} \quad$ Se-Kabupaten Temanggung. skripsi Universitas Negeri Semarang (Unnes). Diakses pada tanggal 8 Februari 2021. https://lib.unnes.ac.id/17893/1/42014 05039.pdf

[4] Sugiyono. Metodologi Penelitian Pendidikan Kuantitatif. Bandung: Alfabeta. 2014

[5] Suryani Ari. 2016. Manajemen Laboratorium Kompetensi Keahlian administrasi Perkantoran SMK Hamong Putera 1 Pakem. Skripsi Fakultas Ekonomi Universitas Yogyakarta. Diakses tanggal 6

Februari

http://eprints.uny.ac.id/43416/1/17.\% 20SKRIPSI_ARI\%20SURYANI_124 02241008.pdf

[6] Susilowati. 2012. Administrasi dan Inventarisasi Alat Laboratorium Sains Sekolah. Makalah yang Disampaikan Dalam Rangka Pengelolaan laboratorium IPA UNY Sabtu, Minggu (3 dan 11 Maret 2012).

Diakses Pada tanggal 8 Februari 2020. http://staffnew.uny.ac.id/upload/1983 06232009122005/pengabdian/admini strasi-dan-pengelolaan-laboratoriumipa.pdf

[7] Verdamawan, R. 2015. Pengelolaan Laboratorium. Jurnal Metana, Vol. 11
No. 02, Desember 2015, Hal. 41 - 46. Diakses pada tanggal 8 Februari 2020. 